\title{
Language and Culture are Two Potential Misunderstanding Sources in Cross-Cultural Clinical Encounters
}

\author{
Nabi Fatahi* \\ University of Gothenburg, Sweden
}

*Corresponding author: Nabi Fatahi, Department of Learning and Leadership for Health Care Professionals, Institute of Health and Care Sciences, The Sahlgrenska Academy, University of Gothenburg, Gothenburg, Sweden

\section{ARTICLE INFO}

Received: 慧 November 15, 2019

Published: 慧 November 22, 2019

Citation: Nabi Fatahi. Language and Culture are Two Potential Misunderstanding Sources in Cross-Cultural Clinical Encounters. Biomed J Sci \& Tech Res 23(2)-2019. BJSTR. MS.ID.003862.

\section{ABSTRACT}

Because of natural disasters, war and ethnical conflicts during the recent years in some parts of the world, a large number of people replaced outside their own language and culture. This issue has led to increase interpreters mediate clinical encounters. In order to minimize clinical communication misunderstanding and improve patient safety, interpreter's competence is essential. As clinical communication is the first stage of a healthcare and medical treatment for patients, satisfactory clinical encounters should be in focus. Misunderstanding in clinical communication may rooted in culture or insufficient language abilities, therefore a strong language bridge that has capacity for transfer of both languages needed.

\section{Introduction}

Every day, healthcare professionals meet a large number of people with language and cultural diversities, which do not share the same language. In these cases, an interpreter should fascinate encounters between partners [1]. In a study of a group of patients from Bangladesh in England, has indicated that communication is the first problem that should be in focus. The study points out that the interpreter's qualification is crucial for providing an adequate care and treatment to immigrant patients at the same level as the native inhabitance [2]. The use of unqualified interpreter reduces the exchange of information between patient and physician, which is of crucial importance for diagnosis and treatment [3]. Such characteristics can be found in interpreters with proficiency in both sources and target languages and basic knowledge of culture and norms in the target language. Furthermore, she/he should be well acquainted with the subject area he/she works with and have knowledge of terminology and laws governing the subject area [4]. In order to deliver satisfactory health service to patients that do not share the same mother tongue with health care professional, not only language but also culture, gender and the nature of communication should consider as influencing factors [5]. Lack of professional interpreter in contact with patient with language barrier and use of relative or family member as interpreter resulted to insufficient clinical encounter and unsatisfactory communication outcome [6,7]. In a study in Sweden concerning clinical communication through interpreter in 39\% of cases, family members used as interpreter, which $6 \%$ of them were children that acted as interpreter for their parents. Family member are not neutral, and their language competence are not good enough to act as interpreter [8]. Healthcare professional basic knowledge about cultural diversity and assigning interpreter base on patient corral background is essential to prevent clinical misunderstanding [9].

\section{Case Report}

\section{Case1 Culture}

A 55-year-old woman who had gastrointestinal pain sought care at a health center in Sweden. She came to Sweden as a family connection seven months ago, but her husband lived in Sweden as a political refugee about 5 years and could speak Swedish quite well, therefore she acted he interpreted for his wife. After a process of investigation, the woman disease was diagnosed as colon cancer. 
In Sweden, if a person is dignified as a cancer patient, she/he will be informed by a health care team both psychologist and social worker are parts of the team. The woman was called to a meeting with the team to be informed of her cancer disease. The doctor who was responsible for the woman's investigation process ordered a professional interpreter to inform the woman about the cancer disease. The woman's husband was present when the woman was informed about the cancer disease. When he found out about the illness he was getting upset and cray, "You are not right to do it, no, no is not absolutely acceptable in our culture. You should never inform her about her cancer, I who should get the information not my bad wife".

\section{Case 2 Language}

A newly arrived asylum seeker seeks doctors for gastrointestinal problems. There was no interpreter in the health center. Accidently in Sweden there are two ways to use an interpreter in clinical encounters, face-to face interpreting or interpreter through telephone. The mother tongue of the patent was a particularly small dialogue in the Kurdish language, which was impossible to find an interpreter in the area that patient found contact in the city that patient sought care. Doctors were trying to hire an interpreter from other places in the country to interpret through telephone. "Now a voice comes from the phone", said the doctor to the patient by pointing to a small speaker that stood with the phone. The interpreter first introduced himself to the doctor and then started in the patients' native language and introduced himself to the patient. "Ask him what kind of problems he has for what he has sought care" that led him to seek care?" The interpreter translated the doctor's message for the pathetic."chen sale dile kzeme her chi de xom le se dilm deweste" From a few years back I have had Stomach burning, all that I eat stays in my heart. The word "dilekze" is useing for Stomach burning or gastric ulcer in a patient's mother tongue. The interpreter's incompetence in the Swedish language as well as lack of knowledge in medicine terminology he translates the patient's message word for word instead of interpreting of the message. Because of misunderstanding, the patient has been send to ECG without having any heart problem

\section{Discussion}

Lingual and cultural misunderstanding in clinical encounters considered as significant sources that infuse communication outcome and patients' safety. Although language misunderstanding often measures as potential factor to clinical misunderstanding because of insufficient knowledge in difference of medicine and health terminology in deferentlanguages [10]. butmisunderstanding that rooted in cultural diversity sometimes is more risk able than the language misunderstanding. Even though is similarity in the biological nature of disease in different culture, but how one express illness and health is varying between driftnet societies [11]. Furthermore, in some culture's information about lethal diseases like those that cancer should give to the patient family rather than patient [12]. Cultural misunderstanding is often changes to a kind of series misunderstanding, when the happened the first one may also continue to the second and third misunderstanding. The following citrate is a series misunderstanding. "I had not visited my mother since 1984. I was sad. I sought assistance from my social worker. I told her, I am missing my mother very much, and I wonder if she could help me so that my mother comes to Sweden. I said, I am very sad; I have no choice other than to kill myself. A day later, I got an appointment at the psychiatric clinic. That was a catastrophe for me; I never forget that she had thought that I was mad" [13]. The first misunderstanding "to kill myself" is a common expression in the client's culture but is a threatening express in Swedish couture. The second misunderstanding "she had thought that I was mad" to visit a psychology or psychiatric clinic is a normal event in Sweden but considered as a catastrophe in client's culture. Competence in both language and culture are essential to prevent communication misunderstanding. An interpreter who interprets in his mother tongue area (bilingual interpretation) with proficiency in the Swedish language and basic knowledge of culture and norms in Sweden. The interpreter should be well acquainted with the subject area he / she works with and have knowledge of terminology and laws governing the subject area [4].

\section{Conclusion}

With cross-cultural clinical encounters both Language and culture should consider as influencing factors concerning communication misunderstanding. Although language is often revile as the actual sours of misunderstanding, but sometimes culture is more capable for communication misunderstanding than the language. To minimize cross-cultural misunderstanding and approve health outcome and patent's' safety language and culture competence interpreter is crucial.

\section{Acknowledgement}

None.

\section{Conflict of Interest}

No conflict of interest.

\section{References}

1. Fatahi N (2018) Using a Competent Interpreter in Clinical Encounters to Prevent Human Suffering and Save Money. JJ Com Med 4(2): 035.

2. Jaggi A, Bithell C (1995) Relationship between physiotherapist's level of contact, cultural awareness and communication with Bangladeshi patients in two health authorities. Physiotherapy 81(5): 330-337.

3. Monroe AD, Shirazian T (2004) Challenging linguistic barriers to health care: students asmedical interpreters. Acad Med 79 (2): 118-122.

4. Fatahi N (2006) Cross-cultural health communication through interpreter. Gothenburg: University of Gothenburg department of primary healthcare thesis.

5. Williams A, Oulton K, Sell D, Wray J (2018) Healthcare professional and interpreter perspectives on working with and caring for non-English speaking families in a tertiary paediatric healthcare setting. Ethn Health 23(7): 767-780 
6. Jaeger FN, Pellaud N, Laville B, Klauser P (2019) The migration-related language barrier and professional interpreter use in primary health care in Switzerland. BMC Health Serv Res 19(1): 429.

7. Pines RL, Jones L, Sheeran N. Health Commun (2019) Using Family Members as Medical Interpreters: An Explanation of Healthcare Practitioners' Normative Practices in Pediatric and Neonatal Departments in Australia 5: 1-8.

8. Fatahi N (2010) Cross-Cultural encounters through interpreter Experiences of patients, interpreters and healthcare professionals. thesis. Göteborgs universtitet.

9. Fatahi N, Hellström M, Skott C, Mattsson B (2008) General practitioners' views on consultations with interpreters: a triad situation with complex issues. Scand J Prim Health Care 26(1): 40-45.

\section{ISSN: 2574-1241}

DOI: $10.26717 /$ BJSTR.2019.23.003862

Nabi Fatahi. Biomed J Sci \& Tech Res

(C) This work is licensed under Creative

Submission Link: https://biomedres.us/submit-manuscript.php
10. Koch Weser S, Dejong W, Rudd RE (2009) Medical word use in clinical encounters. Health Expect 12(4): 371-382.

11. Bishop GD (2002) Health and illness: Mental representations in different cultures. In: International Encyclopaedia of the Social \& Behavioural Sciences. Singapore: National University of Singapore'.

12. Kleinman A (1988) Illness unto death. The Illness Narratives. Suffering healing and the human condition. New York: Basic books, USA.

13. Fatahi N, Nordholm L, Mattsson B, Hellström M (2010) Experiences of Kurdish war-wounded refugees in communication with Swedish authorities through interpreter. Patient Educ Couns 78(2): 160-165.

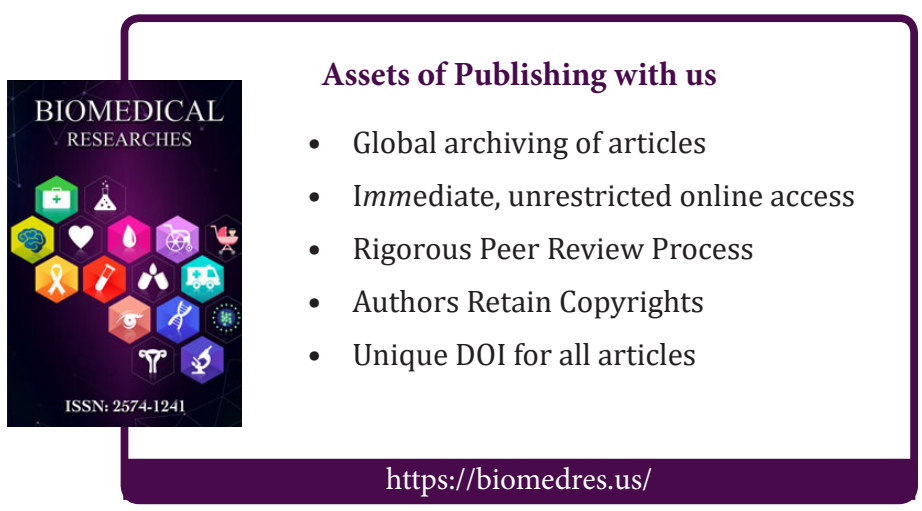

